\title{
Evaluation of prooxidant-antioxidant balance in in vitro fertilization-conceived mice
}

\author{
Hamid Ahmadi' ${ }^{1}$ Fardin Fathi ${ }^{2}$, Ashraf Moeini ${ }^{3}$, Fardin Amidi ${ }^{1}$, Aligholi Sobhani ${ }^{1}$ \\ 'Department of Anatomy, Medical School, Tehran University of Medical Sciences, Tehran; ${ }^{2}$ Cellular and Molecular Research Center, School of Medicine, \\ Kurdistan University of Medical Sciences, Sanandaj; ${ }^{3}$ Department of Obstetrics and Gynecology, Arash Women's Hospital, Tehran University of Medical \\ Sciences, Tehran, Iran
}

Objective: Concerns about the safety of assisted reproductive technology (ART) have been raised, as some studies have shown elevated incidence rates of childhood cancer, asthma, allergies, and other diseases in ART-conceived babies. Findings regarding the health of ART-conceived babies are controversial. The present study was conducted to evaluate the prooxidant-antioxidant balance (PAB) in in vitro fertilization (IVF)conceived mice in comparison to naturally conceived offspring.

Methods: Mice (6-8 weeks) were divided into two groups (IVF-conceived and naturally conceived) matched by sex, age, weight, and litter size. A 1-mL blood sample was taken and the sera were separated. The oxidant-antioxidant balance was evaluated using a fast and reliable PAB assay. The results were expressed as mean \pm standard deviation.

Results: The mean PAB values (HK units) in the IVF-conceived and naturally conceived groups were $59.70 \pm 22.30$ and $54.70 \pm 18.22$, respectively $(p=0.82)$.

Conclusion: Since free radicals contribute to several pathological conditions and antioxidants play an important protective role against oxidative stress, evaluating the oxidant-antioxidant balance is very important. Although the results of this study showed that the quality of the defense mechanism against free radicals was not significantly different between the IVF-conceived and naturally conceived mice, other parameters of metabolic dysfunction need to be measured.

Keywords: In vitro fertilization; Mice; Offsprings; Oxidative stress; Prooxidant-antioxidant balance

\section{Introduction}

The use of assisted reproductive technology (ART), especially in vitro fertilization (IVF), has been increasing; children conceived by ART now account for $0.2 \%-4.2 \%$ of all births worldwide, and the rates are even higher in some developed countries [1]. Generally, the IVF tech-

Received: Mar 30, 2018 · Revised: May 25, 2018 · Accepted: Jun 8, 2018 Corresponding author: Aligholi Sobhani

Department of Anatomy, Medical School, Tehran University of Medical Sciences, no. 3, 16 Azar st, Enghelab Ave 14155-6447, Tehran, Iran

E-mail:sobhania@tums.ac.ir

*This work was supported by the Research Deputy of Tehran University of Medical Sciences (No. 29860).

This is an Open Access article distributed under the terms of the Creative Commons Attribution Non-Commercial License (http://creativecommons.org/licenses/by-nc/4.0/) which permits unrestricted non-commercial use, distribution, and reproduction in any medium, provided the original work is properly cited. nique involves several procedures, including ovarian stimulation, oocyte retrieval and culture, in vitro insemination with capacitated spermatozoa, embryo culture, and transfer of embryos into the uterus. In order to optimize conditions for achieving the best results, these steps have been continuously improved. As with other emerging technologies, risks associated with IVF cannot be excluded. Therefore, several studies have investigated risks associated with infertility treatments [2-5].

The preimplantation period is highly sensitive to environmental changes. Animal studies have suggested that oxidative, nutritional, and in vitro stress restricted exclusively to this period are sufficient to alter developmental, growth, and metabolic trajectories, leading to several pathologies in adulthood [6-8]. It has been reported that even optimized IVF conditions are sufficient to reprogram adult metabolism $[9,10]$. Studies investigating the impacts of systemic oxida- 
tive stress, mitochondrial dysfunction, and impaired insulin and adipose signaling in adult insulin-sensitive tissues have indicated that preimplantation stress can have lasting developmental consequences [11].

Free radicals and reactive oxygen species (ROS) are produced during normal cellular metabolism. Most of the body's energy is produced within the mitochondria during oxidative metabolism, via the enzymatically controlled reaction of oxygen with hydrogen in a process known as oxidative phosphorylation, during which free radicals are formed [12]. Free radicals may be involved in carcinogenesis through the induction of mutations in various genes and by influencing signal transduction and transcription factors [13]. Moreover, oxidative stress plays a critical role in several pathological conditions, such as hypertension, atherosclerosis, and ischemia/perfusion injuries $[14,15]$.

The human body has developed several antioxidant strategies to protect itself against damage from ROS. This allows for normal oxidative metabolism to occur without damaging cells, as well as normal ROS-mediated cellular responses such as the destruction of infectious pathogens and intracellular signaling [16]. Oxidative stress occurs when the production of ROS overwhelms the antioxidant defense mechanisms, leading to cellular damage and inflammation [17]. Several methods have been developed to evaluate oxidant and antioxidant activities separately $[18,19]$.

The prooxidant-antioxidant balance (PAB) method was developed in order to provide a rapid and reliable quantification of the oxidant/ antioxidant balance $[20,21]$. It has been suggested that manipulation in vitro subjects the highly sensitive preimplantation embryo to stress that may have long-lasting effects in adulthood. Therefore, we produced IVF-conceived mice and assessed the oxidative stress in their sera by the PAB method after exposing them to stress. The main aim of the present study was to compare the antioxidant defense mechanisms in IVF-conceived offspring versus offspring conceived under natural conditions.

\section{Methods}

\section{Animals}

Male and female CD1 and NMRI mice were obtained at 6 weeks of age from the Pasteur Institute (Tehran, Iran). Sperm and oocytes were obtained from CD1 mice, while NMRI females were used as surrogate mothers. Mice were fed ad libitum with a standard diet and kept in a temperature- and light-controlled room in pathogen-free conditions $\left(22^{\circ} \mathrm{C}, 12\right.$ hours light $/ 12$ hours dark, $50 \% \pm 10 \%$ humidity). This study was approved by the Institutional Animal Care and Use Committee of Tehran University of Medical Sciences.

\section{Preparation of oocytes}

CD1 females (8-12 weeks old) were injected with 7.5 IU of pregnant mare serum gonadotropin (Sigma, St. Louis, MO, USA) followed by $7.5 \mathrm{IU}$ of human chorionic gonadotropin (hCG) (Sigma) 48 hours later. Oocytes were collected from the oviducts 15 hours after hCG injection by oviduct recession after the mice had been sacrificed by cervical dislocation.

\section{IVF and natural conception}

Immediately after cervical dislocation, sperm samples were collected from the cauda epididymis of mature male CD1 mice. The collected sperm cells were transferred into a $100 \mathrm{~mL}$ drop of human tubal fluid (HTF) medium (Sigma-Aldrich, Taufkirchen, Germany), then incubated at $37^{\circ} \mathrm{C}$ for 1.5 hours to allow capacitation, and the cell count was adjusted to a final concentration of 1 million sperm per milliliter. Then, $1 \times 10^{5}$ sperm cells were added to cumulus-oocyte complexes in HTF medium and incubated at $37^{\circ} \mathrm{C}$ for 5 hours. Subsequently, the fertilized zygotes were washed serially to eliminate the excess of spermatozoa, cumulus cells, and debris, and transferred into a drop of potassium simplex optimization medium (KSOM-AA, Sigma-Aldrich). The embryos were incubated in KSOM medium until they reached the blastocyst stage, and then were transferred into the uteri of pseudopregnant NMRI females. For the production of naturally conceived offspring, a female mouse was put into the cage of a male mouse, and the next morning, they were assessed for the presence of a vaginal plug. Afterward, those with vaginal plugs were placed in separate cages until the day of delivery.

\section{Pseudopregnant females and embryo transfer}

In order to prepare the surrogate uterus, female and vasectomized male NMRI mice were mated overnight. The next morning, they were separated and assessed for the presence of a vaginal plug. Female mice with vaginal plugs were considered pseudopregnant. Then, 7-10 blastocysts were transferred into each horn of the uterus.

\section{Experimental groups}

Mice (6-8 weeks) were divided into two groups (IVF vs. natural conception), with 10 animals in each group. They were matched by sex, weight, age, and litter size (Table 1). The mice were exposed to immobilization stress, as described by Pare and Glavin [22] with some adjustments.

Briefly, for 7 consecutive days the mice were exposed to immobilization stress for 1 hour in addition to 2 minutes of handling. On the day of testing, they were subjected to restraint stress by placing each of them in a $50-\mathrm{mL}$ Falcon tube for 40 minutes. All mice were sacrificed by cervical dislocation. Blood samples were taken by cardiac puncture and sera were separated for the PAB assay. Approximately 
Table 1. Basal characteristics and IVF outcomes

\begin{tabular}{|c|c|c|c|c|c|c|c|c|c|c|}
\hline \multirow{2}{*}{ No. } & \multicolumn{2}{|c|}{ Weight (g) } & \multirow{2}{*}{$\begin{array}{l}\text { Birth } \\
\text { rate (\%) }\end{array}$} & \multirow{2}{*}{$\begin{array}{l}\text { No. of } \\
\text { offspring }\end{array}$} & \multirow{2}{*}{$\begin{array}{l}\text { No. of } \\
\text { recipients }\end{array}$} & \multirow{2}{*}{$\begin{array}{c}\text { Fertilization } \\
\text { rate (\%) }\end{array}$} & \multirow{2}{*}{$\begin{array}{l}\text { No. of ovulated } \\
\text { oocytes }\end{array}$} & \multirow{2}{*}{$\begin{array}{c}\text { No. of } \\
\text { embryos }\end{array}$} & \multirow{2}{*}{$\begin{array}{l}\text { No. of } \\
\text { transferred } \\
\text { embryos }\end{array}$} & \multirow{2}{*}{$\begin{array}{l}\text { No. of oocyte } \\
\text { donors }\end{array}$} \\
\hline & IVF & Control & & & & & & & & \\
\hline 1 & 21 & 20.6 & 27.27 & 6 & 1 & 69 & 36 & 25 & 22 & 2 \\
\hline 2 & 22 & 21.2 & 24.13 & 7 & 2 & 77.5 & 40 & 31 & 29 & 3 \\
\hline 3 & 20 & 19.5 & 24 & 6 & 1 & 78.12 & 32 & 25 & 25 & 2 \\
\hline 4 & 18 & 18.4 & 22.22 & 4 & 1 & 76 & 25 & 19 & 18 & 2 \\
\hline 5 & 19.4 & 19.1 & 21.42 & 3 & 1 & 80 & 20 & 16 & 14 & 2 \\
\hline 6 & 21 & 20.2 & 23.33 & 7 & 2 & 85.7 & 42 & 36 & 30 & 3 \\
\hline 7 & 18.7 & 19.3 & 25 & 5 & 1 & 77.77 & 36 & 28 & 20 & 3 \\
\hline 8 & 19.2 & 18.6 & 26.08 & 6 & 1 & 80 & 25 & 20 & 23 & 2 \\
\hline 9 & 20.4 & 19.9 & 20 & 3 & 1 & 75 & 24 & 18 & 15 & 2 \\
\hline 10 & 23.1 & 22.8 & 28 & 7 & 1 & 83.33 & 36 & 30 & 25 & 2 \\
\hline
\end{tabular}

From each IVF cycle, one offspring was selected and matched to the control group according to sex, weight, age, litter size, and health status. IVF, in vitro fertilization.

1-mL blood samples were collected from each animal. The blood samples were centrifuged, and the sera were separated and then stored at $-80^{\circ} \mathrm{C}$ until use.

\section{Chemicals}

All required chemicals were obtained from Sigma.

\section{PAB assay}

The PAB assay was performed as explained in detail by Alamdari et al. [21]. This method was used to measure the balance between prooxidant and antioxidant factors.

\section{Preparation of solution}

\section{1) 3,3,5,5'-Tetramethylbenzidine cation}

Sixty milligrams of 3,3'5,5'-tetramethylbenzidine (TMB) powder was dissolved in $10 \mathrm{~mL}$ of dimethyl sulfoxide (DMSO) solution. In order to prepare the TMB cation, $20 \mathrm{~mL}$ of acetate buffer $(0.05 \mathrm{M}$ buffer, $\mathrm{pH}=4.5), 400 \mu \mathrm{L}$ of TMB/DMSO, and $70 \mu \mathrm{L}$ of chloramine $\mathrm{T}(100 \mathrm{mM})$ were mixed together and incubated in room temperature for 2 hours in a dark place. After incubation, $25 \mathrm{IU}$ of peroxidase was added to the solution, which was dispensed in 1-mL aliquots and stored at $-20^{\circ} \mathrm{C}$.

\section{2) TMB solution}

The TMB solution was prepared by adding $200 \mu \mathrm{L}$ of prepared TMB/ DMSO solution to $10 \mathrm{~mL}$ of acetate buffer $(0.05 \mathrm{M}$ buffer, $\mathrm{pH}=5.8)$.

\section{3) Working solution}

The working solution was prepared by dissolving $1 \mathrm{~mL}$ of the TMB cation solution into $10 \mathrm{~mL}$ of TMB solution, followed by incubation at room temperature for 2 minutes in a dark place. This solution should be used fresh.

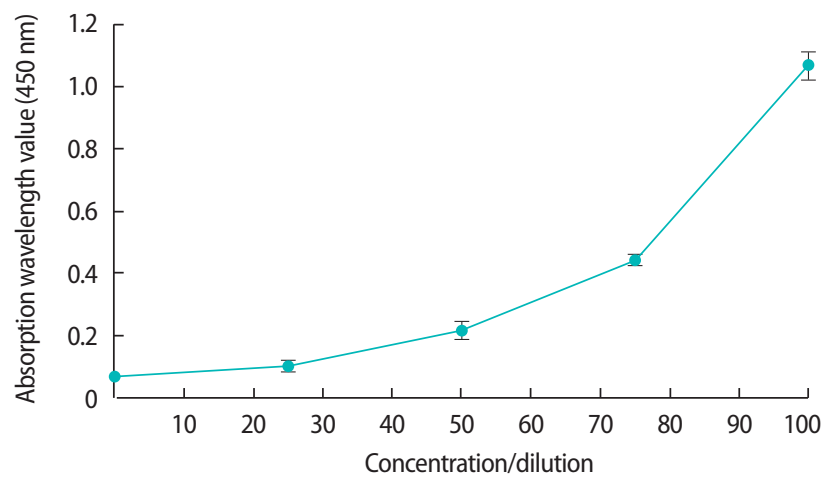

Figure 1. The standard curve of different standard concentrations and corresponding optical density values at $450 \mathrm{~nm}$.

\section{PAB assay}

Using dedicated wells for standards and blanks, $10 \mu \mathrm{L}$ of serum samples and $200 \mu \mathrm{L}$ of working solution were added into each well of a 96-well plate, and incubated at $37^{\circ} \mathrm{C}$ for 12 minutes in a dark place. At the end of the incubation, $100 \mu \mathrm{L}$ of stop solution ( $2 \mathrm{~N} \mathrm{HCl}$ ) was added to each well. Hydrogen peroxidase was used as a standard in different concentrations ( $0 \%-100 \%)$. A standard curve was generated (Figure 1), and the optical density of individual samples was measured at $450 \mathrm{~nm}$ using a Nanodrop instrument (Synergy HTX; Biotek, Winooski, VT, USA).

\section{Statistical analyses}

The results are expressed as mean \pm standard deviation. Statistical analysis was performed using analysis of variance. Differences were considered significant at $p<0.05$.

\section{Results}

Table 1 shows the characteristics and number of ovulated oocytes, 
Table 2. Comparison of PAB values between the IVF-conceived and naturally conceived offspring

\begin{tabular}{lcc}
\hline No. & IVF & Control \\
\hline 1 & $79 \pm 15$ & $85 \pm 12$ \\
2 & $25 \pm 6$ & $51 \pm 12$ \\
3 & $73 \pm 10$ & $42 \pm 16$ \\
4 & $34 \pm 9$ & $73 \pm 18$ \\
5 & $71 \pm 15$ & $39 \pm 11$ \\
6 & $25 \pm 9$ & $75 \pm 15$ \\
7 & $56 \pm 13$ & $50 \pm 9$ \\
8 & $59 \pm 14$ & $26 \pm 11$ \\
9 & $88 \pm 19$ & $48 \pm 19$ \\
10 & $57 \pm 17$ & $58 \pm 14$ \\
Total $^{(a)}$ & $59.70 \pm 22.30$ & $54.70 \pm 18.22$ \\
\hline
\end{tabular}

Values are presented as mean \pm standard deviation.

$\mathrm{PAB}$, prooxidant-antioxidant balance; IVF, in vitro fertilization.

${ }^{\text {a) }} p$-value for mean difference $=0.82$.

the number of fertilized oocytes and transferred embryos, and the birth and fertilization rates. The offspring were selected and matched according to sex, weight, age, litter size, and health status. Ten cycles of IVF were done, and in each cycle 1 offspring was matched with another from a natural cycle as a control.

Table 2 shows the PAB values of each subject (HK units) in the two groups, as well as the mean and standard deviation of both groups. The mean PAB value in the IVF group was slightly higher than that of the natural-conception group, but not to a statistically significant extent $(p=0.82)$.

\section{Discussion}

Concerns about the health of ART-conceived babies have been raised. The major concern is whether ART techniques themselves exert a negative influence on offspring, or whether trends for poorer outcomes are the result of parental characteristics related to the etiology of subfertility per se [23]. Some studies have evaluated the hospitalization rate of IVF-conceived babies, but the results are controversial. Kallen et al. [24] showed an elevated rate of asthma and bronchitis among IVF-conceived babies, but this has not been confirmed by other studies [25]. A small study by Cetinkaya et al. [26] showed no significant difference in the frequency of asthma, allergic rhinitis, and atopic dermatitis between IVF-conceived and naturally conceived babies. In contrast, a large Swedish study revealed a statistically significantly higher rate of asthma among children born after IVF, and this seemed to be partly related to paternal subfertility [27]. An association was also found between paternal subfertility and childhood asthma in ART-conceived babies [28].

Several studies have investigated the possible association between
ART and a higher incidence of childhood cancer [29-31]. Significant excess risk for certain childhood cancers, including acute lymphatic leukemia [29], hepatoblastoma, and rhabdomyosarcoma [31], has been found among IVF-conceived babies in comparison to naturally conceived babies. The risk of metabolic syndrome and chronic diseases among adults conceived by IVF has been assessed in some studies. IVF-conceived individuals tend to have higher body fat [32], higher systolic and diastolic blood pressure, and higher levels of blood glucose than naturally conceived adults [33]. In contrast, Sakka et al. [34] showed that blood pressure was higher among ART-conceived individuals, but found no differences in insulin resistance, fasting glucose-to-insulin ratio, adipokine levels, or evidence of lowgrade infection.

Since antioxidants play an important protective role against free radicals and oxidative stress plays a part in the underlying pathology of several conditions, we evaluated the PAB to assess the quality of the defense mechanism against free radicals in IVF-conceived and naturally conceived mice. The results of the present study showed that the mean PAB values were slightly higher in the IVF offspring than in the naturally conceived mice, but the difference was not statistically significant ( $p>0.05)$. However, in the present study, we investigated the PAB using a fast and reliable method that has been developed for these purposes, rather than evaluating the oxidants and antioxidants separately. In the future, other parameters of metabolic dysfunction need to be measured.

Based on the limited results of the current study, it is suggested that stresses experienced during the preimplantation period in IVF procedures may not have long-lasting effects on the offspring in later life. To the best of our knowledge, the present study is the first to evaluate the balance between oxidants and antioxidants in IVF-conceived mice. As described earlier, the safety of ART is controversial, so it is necessary to ensure that ART-conceived babies receive continuous follow-up, and further animal models should be developed for laboratory investigations. Since the techniques and culture media used in animal IVF studies are not exactly the same as those utilized in human IVF, it is impossible to completely extrapolate the results from mice to human IVF.

\section{Conflict of interest}

No potential conflict of interest relevant to this article was reported.

\section{References}

1. White CE. Let IVF take its course, reconceiving procreative liberty for the twenty-first century. Women's Rights Law Report 2013;35:1.

2. Feuer SK, Camarano L, Rinaudo PF. ART and health: clinical out- 
comes and insights on molecular mechanisms from rodent studies. Mol Hum Reprod 2013;19:189-204.

3. Rivera RM, Stein P, Weaver JR, Mager J, Schultz RM, Bartolomei MS. Manipulations of mouse embryos prior to implantation result in aberrant expression of imprinted genes on day 9.5 of development. Hum Mol Genet 2008;17:1-14.

4. Schwarzer C, Esteves TC, Arauzo-Bravo MJ, Le Gac S, Nordhoff V, Schlatt $S$, et al. ART culture conditions change the probability of mouse embryo gestation through defined cellular and molecular responses. Hum Reprod 2012;27:2627-40.

5. Ventura-Junca P, Irarrazaval I, Rolle AJ, Gutierrez Jl, Moreno RD, Santos MJ. In vitro fertilization (IVF) in mammals: epigenetic and developmental alterations. Scientific and bioethical implications for IVF in humans. Biol Res 2015;48:68.

6. Fernandez-Gonzalez R, Moreira P, Bilbao A, Jimenez A, PerezCrespo $M$, Ramirez MA, et al. Long-term effect of in vitro culture of mouse embryos with serum on mRNA expression of imprinting genes, development, and behavior. Proc Natl Acad Sci U S A 2004;101:5880-5.

7. Fernandez-Gonzalez R, Moreira PN, Perez-Crespo M, SanchezMartin M, Ramirez MA, Pericuesta E, et al. Long-term effects of mouse intracytoplasmic sperm injection with DNA-fragmented sperm on health and behavior of adult offspring. Biol Reprod 2008;78:761-72.

8. Kwong WY, Wild AE, Roberts P, Willis AC, Fleming TP. Maternal undernutrition during the preimplantation period of rat development causes blastocyst abnormalities and programming of postnatal hypertension. Development 2000;127:4195-202.

9. Lonergan P, Fair T, Corcoran D, Evans AC. Effect of culture environment on gene expression and developmental characteristics in IVF-derived embryos. Theriogenology 2006;65:137-52.

10. Watkins AJ, Platt D, Papenbrock T, Wilkins A, Eckert JJ, Kwong WY, et al. Mouse embryo culture induces changes in postnatal phenotype including raised systolic blood pressure. Proc Natl Acad Sci U S A 2007;104:5449-54.

11. Feuer SK, Liu X, Donjacour A, Lin W, Simbulan RK, Giritharan G, et al. Use of a mouse in vitro fertilization model to understand the developmental origins of health and disease hypothesis. Endocrinology 2014;155:1956-69.

12. Lobo V, Patil A, Phatak A, Chandra N. Free radicals, antioxidants and functional foods: impact on human health. Pharmacogn Rev 2010:4:118-26.

13. Mates JM, Perez-Gomez C, Nunez de Castro I. Antioxidant enzymes and human diseases. Clin Biochem 1999;32:595-603.

14. Dhalla NS, Temsah RM, Netticadan T. Role of oxidative stress in cardiovascular diseases. J Hypertens 2000;18:655-73.

15. Kasparova S, Brezova V, Valko M, Horecky J, Mlynarik V, Liptaj T, et al. Study of the oxidative stress in a rat model of chronic brain hypoperfusion. Neurochem Int 2005;46:601-11.

16. Valko M, Leibfritz D, Moncol J, Cronin MT, Mazur M, Telser J. Free radicals and antioxidants in normal physiological functions and human disease. Int J Biochem Cell Biol 2007;39:44-84.

17. Bhatnagar A, Aggarwal A. Oxidative stress: a major player in the pathophysiology of systemic lupus erythematosus. In: Laher I, ed. Systems biology of free radicals and antioxidants. Heidelberg: Springer; 2014. p. 2539-59.

18. Berker Kl, Guclu K, Demirata B, Apak R. A novel antioxidant assay of ferric reducing capacity measurement using ferrozine as the colour forming complexation reagent. Anal Methods 2010;2:1770-8.

19. Horoz M, Bolukbas C, Bolukbas FF, Sabuncu T, Aslan M, Sarifakiogullari $\mathrm{S}$, et al. Measurement of the total antioxidant response using a novel automated method in subjects with nonalcoholic steatohepatitis. BMC Gastroenterol 2005;5:35.

20. Alamdari DH, Ghayour-Mobarhan M, Tavallaie S, Parizadeh MR, Moohebati M, Ghafoori F, et al. Prooxidant-antioxidant balance as a new risk factor in patients with angiographically defined coronary artery disease. Clin Biochem 2008;41:375-80.

21. Alamdari DH, Paletas K, Pegiou T, Sarigianni M, Befani C, Koliakos $G$. A novel assay for the evaluation of the prooxidant-antioxidant balance, before and after antioxidant vitamin administration in type II diabetes patients. Clin Biochem 2007;40:248-54.

22. Pare WP, Glavin GB. Restraint stress in biomedical research: a review. Neurosci Biobehav Rev 1986;10:339-70.

23. Pinborg A, Lidegaard O, Freiesleben $\mathrm{Nl}$, Andersen AN. Vanishing twins: a predictor of small-for-gestational age in IVF singletons. Hum Reprod 2007;22:2707-14.

24. Kallen B, Finnstrom O, Nygren KG, Olausson PO. In vitro fertilization in Sweden: child morbidity including cancer risk. Fertil Steril 2005;84:605-10.

25. Klemetti R, Sevon T, Gissler M, Hemminki E. Health of children born as a result of in vitro fertilization. Pediatrics 2006;118:181927.

26. Cetinkaya F, Gelen SA, Kervancioglu E, Oral E. Prevalence of asthma and other allergic diseases in children born after in vitro fertilisation. Allergol Immunopathol (Madr) 2009;37:11-3.

27. Kalen B, Finnstrom O, Nygren KG, Otterblad Olausson P. Asthma in Swedish children conceived by in vitro fertilisation. Arch Dis Child 2013;98:92-6.

28. Carson C, Sacker A, Kelly Y, Redshaw M, Kurinczuk JJ, Quigley MA. Asthma in children born after infertility treatment: findings from the UK Millennium Cohort Study. Hum Reprod 2013;28:471-9.

29. Kallen B, Finnstrom O, Lindam A, Nilsson E, Nygren KG, Olausson PO. Cancer risk in children and young adults conceived by in vitro fertilization. Pediatrics 2010;126:270-6. 
30. Kallen B, Finnstrom O, Nygren KG, Olausson PO. The link between IVF children and cancer: what do we know so far. Reprod Syst Sex Disord 2012;S5:004.

31. Williams CL, Bunch KJ, Stiller CA, Murphy MF, Botting BJ, Wallace $\mathrm{WH}$, et al. Cancer risk among children born after assisted conception. N Engl J Med 2013;369:1819-27.

32. Ceelen $M$, van Weissenbruch MM, Roos JC, Vermeiden JP, van Leeuwen FE, Delemarre-van de Waal HA. Body composition in children and adolescents born after in vitro fertilization or spontaneous conception. J Clin Endocrinol Metab 2007;92:3417-23.
33. Ceelen $M$, van Weissenbruch MM, Vermeiden JP, van Leeuwen FE, Delemarre-van de Waal HA. Cardiometabolic differences in children born after in vitro fertilization: follow-up study. J Clin Endocrinol Metab 2008;93:1682-8.

34. Sakka SD, Loutradis D, Kanaka-Gantenbein C, Margeli A, Papastamataki M, Papassotiriou I, et al. Absence of insulin resistance and low-grade inflammation despite early metabolic syndrome manifestations in children born after in vitro fertilization. Fertil Steril 2010;94:1693-9. 